\title{
ARTICLES
}

\section{Growth Trajectory Evident at Birth Affects Age of First Delivery in Female Monkeys}

\author{
CHRISTOPHER L. COE AND ELIZABETH A. SHIRTCLIFF \\ Harlow Center for Biological Psychology and Department of Psychology, University of Wisconsin, \\ Madison, Wisconsin 53715, U.S.A.
}

\begin{abstract}
Growth trajectories established early in life have proven to be important determinants of metabolism, health in adulthood, and ultimate mortality. The age of sexual maturation may also be set early in development, perhaps etched in utero. The following study used growth curve modeling to investigate the degree to which birth weight and weight gain before sexual maturation constrained the timing of reproduction in 147 female rhesus monkeys living under standardized social and nutritional conditions. Although size at birth by itself did not determine age of reproductive maturation, it was strongly associated with the subsequent developmental growth trajectory, which in turn predicted age at first offspring. In contrast to human studies indicating that small birth size is followed by a postnatal "catch-up" growth phase that accelerates menarche, growth trajectories re-
\end{abstract}

\section{ABSTRACT}

mained distinctive in small and large infant monkeys. Thus, it was the sustained and stable disparity in size already evident at birth and amplified through development that accounted for variation in the age of adult sexual maturity. (Pediatr Res 55: 914-920, 2004)

$\quad$ Abbreviations
M, mean
NFI, normed fit index
NNFI, nonnormed fit index
CFI, comparative fit index
RMSEA, root mean square error of approximation
LBW, low birth weight

Whereas variation in age at puberty was once thought to be due primarily to individual differences in weight, stature, and activity levels in the preadolescent period (1-6), there is now extensive evidence that the timing is constrained by events much earlier in development. The important influence of reduced prenatal growth and LBW was highlighted by Barker (7-10) in relation to a wide variety of metabolic diseases and conditions, but fetal growth also appears to influence the timing of puberty $(11,12)$ and later reproductive success $(13)$. LBW has been reported to be a risk factor for early maturation (14-17), and girls who experience a precocious pubarche $(18-20)$ or early menarche $(21)$ were often of low weight at birth. Normal birth weight girls appear to be protected in part

Received July 29, 2003; accepted November 15, 2004.

Correspondence: Christopher Coe, Ph.D., Harlow Center for Biological Psychology, 22 North Charter St., University of Wisconsin, Madison, WI 53715, U.S.A.; e-mail: ccoe@wisc.edu

Supported by grants from the National Institute of Allergy and Infectious Diseases (AI46521) and National Institute of Child Health and Human Development (HD38305). Partial salary support for C.L.C. was also provided by the Wisconsin Primate Research Center (R000167). E.A.S. is supported by a National Institute of Mental Health training grant on Emotions, T32-MH18931.

DOI: 10.1203/01.PDR.0000125259.45025.4D from such early maturation by progressing more slowly through the pubertal transition, but LBW girls often develop more rapidly once they show the initial bodily signs of hormone activation (21). These observations differ from studies in animals that indicate optimal growth from birth onward accelerates the attainment of adult maturity and frequently endows the individual with greater reproductive success $(22,23)$. Therefore, we re-examined birth and development in female monkeys to provide a cross-species comparison and potentially to add greater credence to several discrepant reports in humans that found higher birth weight was associated with an earlier puberty in normal (24) and growth-restricted girls (25).

Further resolution of discrepancies in the literature may be achieved by considering whether the pattern of postnatal growth remains consonant with birth weight. LBW can be associated with slow growth from infancy through childhood (25-31) such that approximately $15-20 \%$ of children remain of small stature through adolescence $(32,33)$. Adair (12) argued that it is only when LBW girls show "catch-up" growth (26, 34 ), especially those who were long and lean at birth, that they evince an early puberty (see also 35,36 ). It should be noted further that when LBW girls catch up in weight, it is often not 
manifest in their final adult height (21), with 20\% LBW girls being overweight and 15\% obese at age 20 (34). This finding would appear to be in keeping with Barker's hypothesis about the effects of in utero growth restriction and postnatal sufficiency (9). Any potential for accelerated growth would be predicated on a small baby being exposed subsequently to abundant nutritional resources in the rearing environment (3537). On the other end of the spectrum, big babies who just sustain their enhanced growth could be as predisposed for an early puberty, a finding that concurs with the traditional views about larger stature and maturity $(6,11,12,15,38$, but see 39$)$. Although it is not feasible to design a prospective study of pregnant women that controls environmental conditions and standardizes nutrition, it is possible achieve this type of experimental rigor in a breeding colony of monkeys.

Given that growth is commonly theorized to be a mechanism linking birth weight with age at puberty, we also found it a little surprising that the analytic strategies have not usually used modeling techniques that treat postnatal weight gain as a change measure, albeit with some notable exceptions $(12,40)$. Further, some studies opted to statistically control for weight, and found that weight in childhood was an independent predictor of pubertal timing (e.g. 11, 12, 15, 24). This approach potentially underestimates the importance of individual differences in growth trajectories, and places the emphasis primarily on the between-group difference in weight (41). In the present study, growth curve modeling (42) was used to characterize individual differences in birth weight and growth across the first $3 \mathrm{y}$ of the female monkey's life. This age span captures the prepubertal period of maturation in the rhesus monkey, as menarche typically occurs between 2.5 and 3.5 y of age (43). Birth weight and growth were then used to predict differences in the age at first successful delivery of a baby. This method of parameterizing individual differences is optimal because (a) growth is modeled as a change from birth weight, rather than by weight at any specific time point; (b) the influence of birth weight and growth are examined in the same model; (c) unsystematic error variance is partitioned out of the "true" score of weight and growth; (d) individual differences in birth weight and growth are statistically tested; and (e) the predictive values of birth weight and growth are examined in the same model, thereby partialling out the effects of each parameter (42, 44-46).

Previous studies of birth weight patterns in this monkey colony have indicated that the predisposition for large or small babies is a heritable tendency passed from mother to daughter, and that fetal growth and birth weight were strongly associated with the amount of maternal weight gain during pregnancy (47, 48). These new analyses provided an opportunity to assess whether there might also be more sustained consequences for reproductive success persisting into adulthood. Specifically, the modeling was designed to test the following three hypotheses: (a) birth weight would be associated with growth during the prepubertal period and subsequently with age at first delivery; (b) larger size and faster growth would be related to an earlier puberty; and, finally, (c) LBW might be linked with a distinct growth trajectory that delayed the attainment of adult maturity and birth of first offspring.

\section{METHODS}

\section{Subjects}

The data were generated from clinical records on a large breeding colony of rhesus monkeys (Macaca mulatta) maintained under standardized conditions at the University of Wisconsin since the 1960 s $(47,48)$. The current analyses were based on the third-through-fifth generation descendants of animals that originated in India. Information on 147 female monkeys, born between August 1979 and October 1997, and their first offspring, born an average 4.6 y later ( $\mathrm{SD}=0.8)$, was summarized. Inclusion criteria included: (a) birth weight recorded within $3 \mathrm{~d}$ of parturition $(\mathrm{M}=0.6, \mathrm{SD}=0.9 \mathrm{~d})$; (b) complete weight records through the first $3 \mathrm{y}$ of age; and (c) successful delivery of a live baby before the age of $7 \mathrm{y}$. Exclusion criteria included: (a) housing or experimental conditions that restricted normal breeding; (b) sustained or recurrent ill health, such as gastrointestinal infections; or (c) relocation to another facility before reproductive age.

\section{Housing and Rearing Conditions}

This monkey colony typically generates between 50 and 100 infants per year, which are reared normally by their mothers through 6-12 mo of age. Thereafter, they are transferred to small juvenile groups or mixed-age groups where they remain through the birth of their first offspring. The rhesus monkey typically reaches menarche at $2.5 \mathrm{y}$, begins ovulatory cycles at approximately 3.5 y (43), then has a 169-d gestation before giving birth to her first offspring. Environmental and housing conditions were standardized. Water was available ad libitum, a fixed quantity of commercial monkey biscuits was provided in the early morning (from the same vendor, Purina, for the last two decades), and fruit supplements were given in the afternoon. The light-dark schedule was 14:10, with lights on at 0600, which largely overrode the seasonal breeding tendency of this species. ${ }^{1}$ Ambient room temperature was constant at $21^{\circ} \mathrm{C}$. All breeding and research procedures described here in have been approved by the institutional Animal Care and Use Committee.

\section{Measures}

Birth. The date of birth, sex of infant, and its weight have been recorded routinely for several decades. For inclusion in the present study, all infants had to be weighed within $3 \mathrm{~d}$ of parturition. Mean weights taken on d 1-3 $(n=62)$ did not differ from those weights recorded on the day of birth $(n=85)$, $\mathrm{F}_{3,143}=1.68, p=0.17$, pairwise comparison ps $>0.29$. Weights recorded $4 \mathrm{~d}$ after birth $(\mathrm{M}=441 \mathrm{~g}, \mathrm{SD}=44)$, however, were significantly lower than neonatal weights recorded on the day of birth $(\mathrm{M}=500 \mathrm{~g}, \mathrm{SD}=60)$, and hence

\footnotetext{
${ }^{1}$ Retrospective analyses based on birth dates indicated that $60 \%$ of the fertile matings occurred during the months of October through January. This estimate is significantly less than the seasonality effects observed by Terasawa (41) in which $80 \%$ of first ovulatory cycles in the rhesus monkey occurred within these $4 \mathrm{mo}, p<0.0001$, but it is also greater than would be expected by chance $(33 \%, p<0.0001)$. Off-season mating did not affect birth weight, $\mathrm{F}_{1,135}=0.83$, birth category, $\chi_{2}^{2}(n=147)=0.55$, nor the growth trajectory category, $\chi_{2}^{2}(n=147)=0.15, p s>0.61$
} 
any later weighings were not included in the present study, even though monkey infants typically return to their birth weight by 1 wk of age.

The reported weights represent the normal range for this species because infants born premature or extremely small are less likely to survive without human intervention, and only mother-reared babies were included. A previous article has characterized small-for-date monkeys in our colony as weighing $<380 \mathrm{~g}(47,48)$. In the current data analysis, only one monkey was included that weighed $<380 \mathrm{~g}$ or was 2 SD below the mean [a standard clinical cutoff for LBW $(33,34)$ ].

Three groups based on percentile birth weight scores were created to determine whether babies born small or large exhibited different growth trajectories (i.e. to test for catch-up growth). Small (lower 25\%; range, 370-460 g, $n=37$ ) and large babies (upper 25\%; range, 525-755 g, $n=37$ ) were compared with their average counterparts (mid 50\%; range, $460-520 \mathrm{~g}, n=73$ ).

Growth. Complete clinical and experimental records were maintained on all animals, including regular weights. For analyses, weights were summarized at annual intervals through the typical age for menarche, which is between 2.5 and $3.5 \mathrm{y}$ of age (43). For descriptive purposes, three additional groupings were also created on the basis of percentile growth scores (lower $25 \%$, mid $50 \%$, and upper $25 \%$ ) to evaluate the effects of slow, average, or fast growth (which overlapped, but was not necessarily identical to the birth weight categorization).

Reproductive success. The age at delivery of the first viable offspring was the primary outcome variable. Inclusion criteria required that the female was maintained in social housing conditions conducive to reproducing, and had given birth to at least one baby before $7 \mathrm{y}$ of age (i.e. within $3 \mathrm{y}$ of even a late menarche). This inclusion criterion was set because any further delays in reproducing might have been indicative of a gynecological basis for the infertility.

\section{Analytical Strategy}

Growth curve modeling with maximum likelihood estimation was used to evaluate birth weight and growth (Fig. 1). This strategy used latent factors to assess individual differences in the level (birth weight) and slope (growth from birth to $3 \mathrm{y}$ of age). The level and slope were modeled initially at the individual level (49). After it was found that variation around the mean level and slope was systematic, the capacity of level and slope to predict individual differences in age at first delivery was considered (50). Slope across 3 y was linearized to incorporate the faster growth in the first year of life compared with the second and third years (42, see also 51). The $\chi^{2}$ goodness of fit and indices of practical fit were used to assess the fit of the model (52).

The growth curve model was examined initially for all subjects; then, FI procedures (53-55) were used to determine whether growth and age at delivery were similar in infant monkeys that were low, average, or large birth weight using a multiple group approach $(56,57)$. With the exception of birth weight and level, which were different by definition of the grouping factor, the reduction in the fit of the model, when the parameters were constrained to be equal across groups, estimates the size of differences between small, average, and large babies. Obtaining strict FI would allow one to conclude that the model operated similarly in babies of low, average, or large birth weight and would rule out the possibility that small or large babies had different growth functions than babies of average birth weight $(52,53)$.

\section{RESULTS}

The birth weights and growth patterns observed in this colony were typical for the species and representative of female maturation in other colonies (Table 1) (58). At birth, these full-term monkey babies exhibited a wide variation in size, between 370 and $755 \mathrm{~g}$, and then underwent fairly rapid

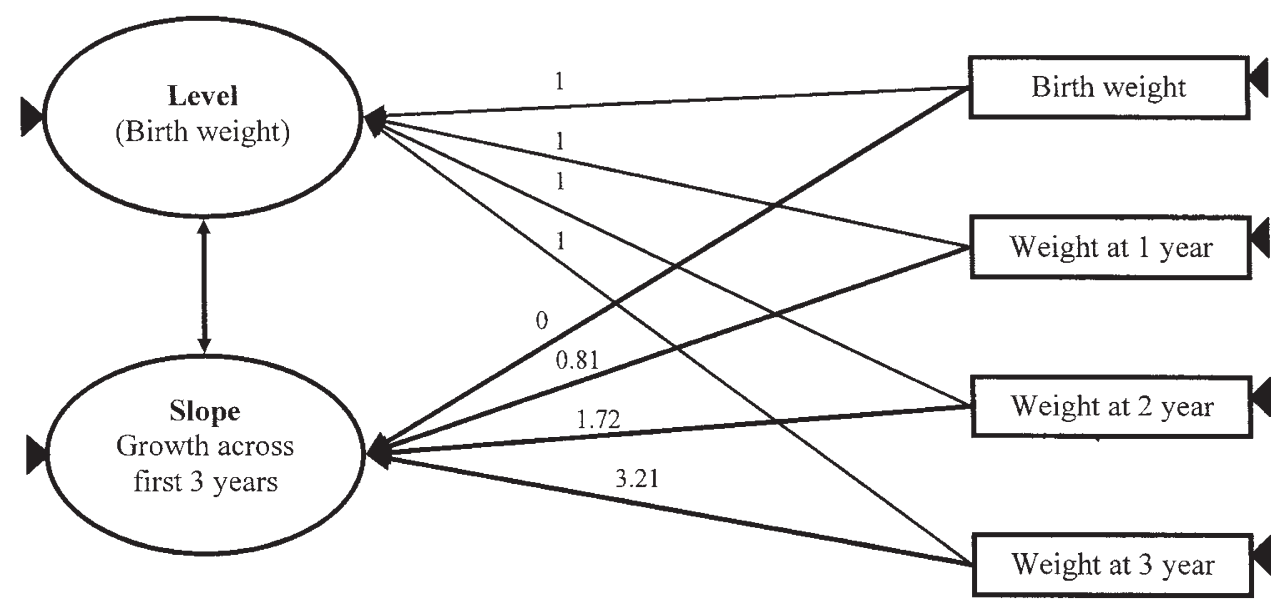

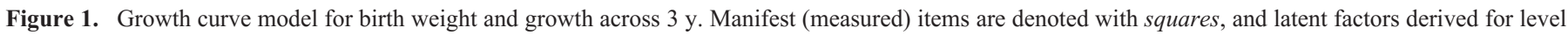

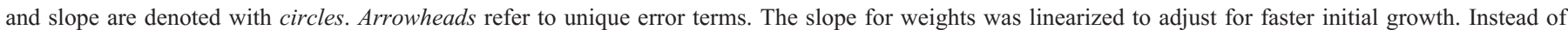

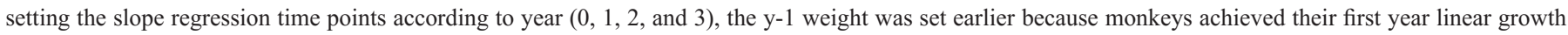
by $0.81 \mathrm{y}(9.7 \mathrm{mo})$, their $\mathrm{y}-2$ linear growth at $1.72 \mathrm{y}(20.6 \mathrm{mo})$, and their $\mathrm{y}-3$ linear growth at $3.21 \mathrm{y}(38.5 \mathrm{mo})$. 
Table 1. Mean (SD) birth weight and growth (in grams) for female rhesus monkeys during first 3 y of life, and age at delivery of their first offspring

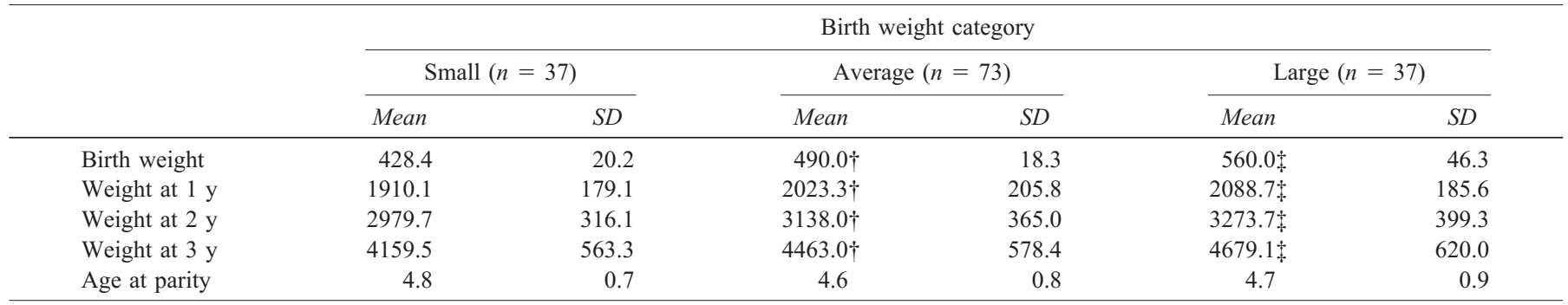

Birth weight continues to be related to size across $3 \mathrm{y}, \mathrm{ps}<0.01$. Age at parity was not significantly different by birth weight when considered as a broad category; however, it was related to the overall difference in size across 3 y of growth (Fig. 3). The symbol $\dagger$ is used when the small group differs from the average group and denotes when the small group differs from the large group.

growth by $1 \mathrm{y}$ of age (range, $1.5-2.7 \mathrm{~kg}$, mean change $=1.5$ $\mathrm{kg}, \mathrm{SD}=0.2$ ). By this point, the infant was eating independently, and based on our normal husbandry practice was rehoused with other juveniles. Weight increased at a slightly slower rate through 2 y (range, $2.1-4.1 \mathrm{~kg}$, mean change $=1.3$ $\mathrm{kg}, \mathrm{SD}=0.4$ ), and continued through $3 \mathrm{y}$ of age (range, $3.2-6.1 \mathrm{~kg}$, mean change $=1.1 \mathrm{~kg}, \mathrm{SD}=0.3$ ), which is the typical age of menarche. Correlations of individual weights across years were highly significant, suggestive of stability in the growth trajectories ( $r$ s range, $0.41-0.71, p$ s $<0.0001$ ).

Growth curve modeling was then used to examine the slope or change in weight from birth through $3 \mathrm{y}$ of age (42). The fit of the basic model was excellent when growth was linearized to account for the accelerated growth in the first year of life, $\chi_{3}^{2}=1.99, p=0.57, \mathrm{NFI}=0.99, \mathrm{NNFI}=1.01, \mathrm{CFI}=1.00$, and RMSEA $=0.001$, indicating that the model accurately captured the structure of the data. Variance estimates for level, $1850, t=2.22, p=0.06$, slope, 24753, $t=6.86, p<0.0001$, and age at birth of first offspring, 79858, $t=8.95, p<0.0001$, were highly significant, demonstrating that there were sufficient individual differences in these measures to be considered acceptable independent and dependent variables. Larger females at birth grew faster across the first three years of life, $r$ $=0.40, p<0.01$.

When age at first delivery was included in the model, the fit was adequate, $\chi_{5}^{2}=9.12, p=0.10, \mathrm{NFI}=0.95$, NNFI $=$ 0.96 , CFI $=0.98$, and RMSEA $=0.08$. Birth weight by itself was not associated with age at first offspring, $r=0.18, p=$ 0.40 , but the slope of growth was inversely associated with age at first offspring, $r=-0.38, p<0.001$ (Fig. 2). Quartiles based on growth trajectories demonstrated that females with the slowest growth trajectory (bottom 25\%) gave birth to their first offspring, on average, at $4.81(\mathrm{SD}=0.78) \mathrm{y}$ of age,

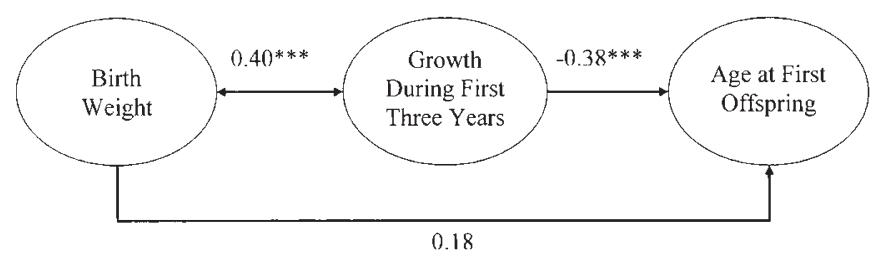

Figure 2. Relationship between birth weight, growth during first $3 \mathrm{y}$, and age at birth of first offspring. Birth weight was indirectly related to age at first offspring. Monkey infants that were larger at birth grew faster and, in turn, had offspring earlier. whereas females with the fastest growth trajectory (top 25\%) gave birth an average of five months earlier $(\mathrm{M}=4.29 \mathrm{y}, \mathrm{SD}$ $=0.76$ ), $\mathrm{F}_{2,144}=5.18, p=0.007$ (Fig. 3).

Three groups were then created to represent monkeys born small, average, or large, to test the hypothesis that the growth trajectories and age at first delivery were affected by birth size. FI procedures demonstrated that strict FI did not substantially reduce the fit of the model (Table 2). Thus, the association between level and slope and the prediction of age at birth of first offspring were similar in all three groups. This indicated that, with the exception of birth weight, the model parameters-variance, covariance, regression weights, and beta weights -were similar in monkeys of small, average, and large birth weight (Table 2). Babies who were born small were 10.4 times more likely to have a slow growth trajectory compared with babies born big. Only $11 \%$ of babies born small evinced a fast growth trajectory, in contrast to $43 \%$ of babies born big, providing further support that big babies tended to grow faster, $\chi_{4}^{2}=12.03, p=0.02$. Further, there was no evidence that the LBW females had a more rapid initial growth trajectory than did the average or large infants (i.e. they did not show signs of postnatal catch-up growth).

\section{DISCUSSION}

These analyses have confirmed that growth patterns starting very early in life have a strong influence on maturational processes related to the attainment of adult reproductive status. Although birth weight by itself did not determine the timing of adult reproduction, the size of the neonate was an important component of the developmental growth trajectory, which in turn had a significant effect on the female monkey's age at first delivery. The findings highlight the importance of considering the association between both pre- and postnatal growth in studies on the effects of LBW $(12,40)$. Because birth weight reflects the earlier processes of fetal growth $(7,8)$, it is likely that critical events related to age of sexual maturation are initiated in utero (11-17), and then are substantiated through growth processes during the prepubertal period $(11,12,15,24$, $26,40,59)$. Consistent with other nonhuman primate research and a number of human studies, bigger babies remained larger and attained sexual maturity earlier than did the smaller and slower-growing offspring $(22,24,25)$. Further, the profile of the growth trajectory was relatively stable across monkeys of 


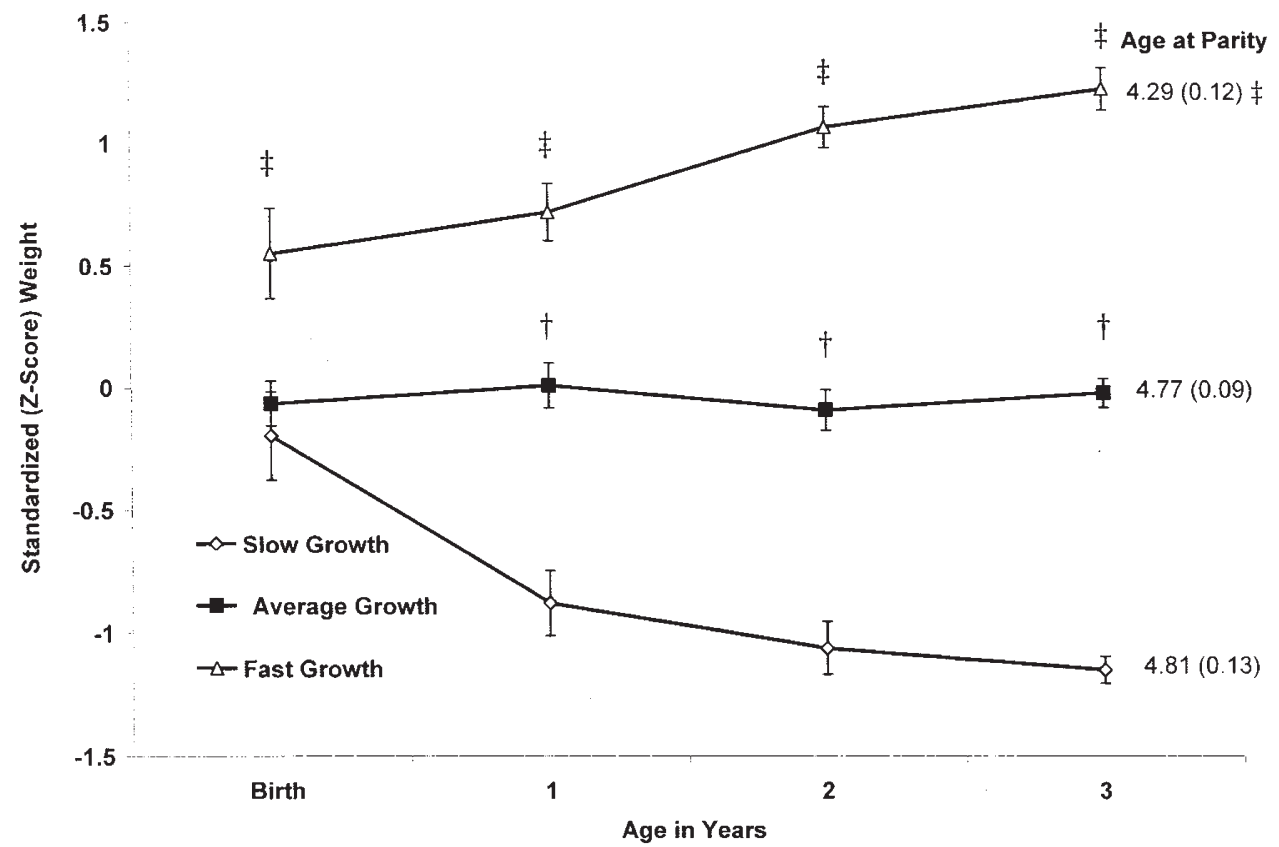

Figure 3. Standardized weight scores during the first 3 y of life in slow-growing (bottom 25\%), average-growing (mid 50\%), and fast-growing (top 25\%) offspring. Monkeys that grew quickly were more likely to be bigger at birth and, subsequently, had offspring at an earlier age than average or slow-growing monkeys. Monkeys that grew slowly across the first 3 y of life were more similar to the average-growing monkeys in birth weight and age at parity. The symbol $\dagger$ denotes when the small group differs from the average group, and $\ddagger$ denotes when the small group differs from the large group.

Table 2. Chi-square goodness of fit $\left(\chi^{2}\right)$ and degrees of freedom (DF) for models testing whether the growth curve model is similar for small, average, and large birth weight babies

\begin{tabular}{|c|c|c|c|c|c|}
\hline Model & $\mathrm{DF}$ & $\chi^{2}$ & $\Delta \mathrm{DF}$ & $\Delta \chi^{2}$ & $p$ Value \\
\hline Unconstrained (a) & 15 & 22.46 & & & \\
\hline Strict Factor Invariance (b) & 25 & 28.35 & 10 & 5.89 & 0.9 \\
\hline Association between level and slope & 27 & 31.85 & $12 \mathrm{a}$ & 9.39 & 0.9 \\
\hline Association with age at first offspring & 31 & 38.34 & $16 \mathrm{a}$ & 15.88 & 0.8 \\
\hline & & & $4 \mathrm{~b}$ & 6.49 & 0.2 \\
\hline
\end{tabular}

Strict FI, constraining the regression weights, means, and unique variance estimates to be equal in small, average, and large birth weight babies, did not substantially reduce the fit of the model. Change in degrees of freedom $(\Delta \mathrm{DF})$ and chi-square $\left(\Delta \chi^{2}\right)$ demonstrates the reduction in the fit of the constrained model when compared to the unconstrained (a) and strict factor invariance (b) model.

different sizes, providing little evidence for postnatal catch-up growth in the smaller infants, but instead demonstrating sustained and stable developmental advantage for larger infants $(2,3)$. Even when a small portion of the LBW monkeys did show some enhanced growth in the postnatal period, they typically entered only the average growth group, and did not cross over to the fastest growing category. Similarly, it was rare for an infant monkey born large to shift all the way to the slow profile of postnatal growth, and if they changed at all, it was just to regress toward the average rate of growth.

Based on these findings, it would appear that growth processes already evident at birth are the primary mediators of the relationship between preterm factors and sexual maturation $(12,40)$. The value of growth curve modeling was that it allowed us to consider birth weight as one point on this continuum, reflecting in utero processes, which then gained additional significance as the growth trajectory extended through postnatal development. Dos Santos Silva and colleagues (40) found that LBW in humans was associated with an early puberty, which is consistent with the majority of the literature. However, when they controlled for growth in infancy as a change measure, high birth weight was associated with early puberty. Similar to our findings in the monkey, when they also controlled for growth in childhood, postnatal growth mediated the relationship between birth weight and puberty. Thus, postnatal growth has the potential to clarify whether small or large babies are at risk for early maturation. Just as pre- and postnatal growth are conceptually important in studies of birth weight and maturation, analyzing growth in the right statistical manner is equally crucial to the interpretation of findings on LBW babies.

There are several possible reasons why we failed to find evidence for either LBW or postnatal catch-up growth as risk factors for early maturation. This project was designed to examine birth weight that was in the normal range for this species, in contrast to our earlier survey of 1321 babies over $25 \mathrm{y}$, which specifically identified a different cohort of LBW monkeys $<380 \mathrm{~g}(47,48)$. Although some studies in humans have demonstrated that small size within the normal range accelerated puberty $(11,12,40)$, the most compelling evidence 
comes from reports on girls born moderately or extremely LBW (14-16). These types of infants were not included in our analyses because our inclusion criteria also required maternal rearing without human intervention: very small or sickly monkeys would be less likely to survive through the birth process and neonatal period (60-63). In addition, catch-up growth does not seem to be as common in babies on the lower end of the normal range as it is in LBW babies $(24,35)$. It appears that the coincidence of a period of malnourishment during pregnancy followed by a more benevolent postnatal rearing environment is the critical factor in changing the timing of puberty (59), just as it appears to accentuate the relationship between LBW and adult disease $(9,36)$. For example in a sheep model, when the placental transfer of nutrients was purposefully restricted only during pregnancy, it resulted in LBW lambs, but their subsequent postnatal growth on a controlled diet was then enhanced, resulting in an accelerated puberty (21). In our case, gravid females were maintained on a standardized and sufficient diet, which was sustained through both the nursing and prepubertal phases, fostering a more normative growth profile and perhaps maximizing the likelihood of stable growth trends in the majority of offspring. To fully understand the relationship between growth in LBW babies and an accelerated puberty, it thus seems that a consideration of the combined effect of intrauterine growth restriction and postnatal diet is required.

Our findings concur with placing greater emphasis on the prenatal period when considering influences on age at menarche, because it appears that the growth trajectory begun during fetal life is the primary constraint. In monkeys, this conclusion becomes even more evident after experimental manipulations that cause radical departures in growth from the norm. For example, when female fetal monkeys were exposed to androgens in utero, it both shifted their growth to a masculine pattern and delayed their menarche until the age when male monkeys normally reach puberty (64). Conversely, when the established growth trajectory was experimentally altered at $1.5 \mathrm{y}$ of age in female monkeys, by lesions in the lateral hypothalamus, the onset of menarche was markedly advanced (65). These observations highlight the fact that both radical and modest manipulations of the pre- and postnatal environment can have long-term effects on the timing of sexual maturation, which are amplified through growth. Taking this extended developmental perspective is of value for evaluating the significance of birth weight when it is used as the primary outcome measure in a pregnancy study (66). Similarly, a modeling of trajectory can also be of value for interpreting observations on shifts in the timing of puberty due to seemingly discrete events that occur during childhood (67).

Acknowledgments. The authors thank H. Crispen and $\mathrm{M}$. Luck for their assistance in animal husbandry and record-keeping.

\section{REFERENCES}

1. Cole TJ 2000 Secular trends in growth. Proc Nutr Soc 59:317-324

2. Rogol AD, Clark PA, Roemmich JN 2000 Growth and pubertal development in children and adolescents: effects of diet and physical activity. Am J Clin Nutr $72: 521 \mathrm{~S}-528 \mathrm{~S}$
3. Bourguignon JP 1991 Growth and timing of puberty: reciprocal effects. Horm Res 36:131-135

4. Roemmich JN, Richmond RJ, Rogol AD 2001 Consequences of sport training during puberty. J Endocrinol Invest 24:708-715

5. Brooks-Gunn J 1988 Antecedents and consequences of variations in girls' maturational timing. J Adolesc Health Care 9:365-373

6. Foster DL, Nagatani S 1999 Physiological perspectives on leptin as a regulator of reproduction: role in timing puberty. Biol Reprod 60:205-215

7. Barker DJ 1995 Intrauterine programming of adult disease. Mol Med Today 1:418 423

8. Barker DJ 1994 Outcome of low birthweight. Horm Res 42:223-230

9. Barker DJ 1995 The fetal and infant origins of disease. Eur J Clin Invest 25:457-463

10. Barker DJ 1990 The fetal and infant origins of adult disease. BMJ 301:1111

11. Cooper C, Kuh D, Egger P, Wadsworth M, Barker D 1996 Childhood growth and age at menarche. Br J Obstet Gynaecol 103:814-817

12. Adair LS 2001 Size at birth predicts age at menarche. Pediatrics 107:E59

13. Lumey LH, Stein AD 1997 In utero exposure to famine and subsequent fertility: the Dutch Famine Birth Cohort Study. Am J Public Health 87:1962-1966

14. Voordouw JJ, van Weissenbruch MM, Delemarre-van de Waal HA 2003 Intrauterine growth retardation and puberty in girls. Twin Res 4:299-306

15. Koziel S, Jankowska EA 2002 Effect of low versus normal birthweight on menarche in 14-year-old Polish girls. J Paediatr Child Health 38:268-271

16. Persson I, Ahlsson F, Ewald U, Tuvemo T, Qingyuan M, von Rosen D, Proos L 1999 Influence of perinatal factors on the onset of puberty in boys and girls: implications for interpretation of link with risk of long term diseases. Am J Epidemiol 150:747755

17. Ibanez L, Potau N, Marcos MV, de Zegher F 1999 Exaggerated adrenarche and hyperinsulinism in adolescent girls born small for gestational age. J Clin Endocrinol Metab 84:4739-4741

18. Ibanez L, Potau N, Francois I, de Zegher F 1998 Precocious pubarche, hyperinsulinism, and ovarian hyperandrogenism in girls: relation to reduced fetal growth. J Clin Endocrinol Metab 83:3558-3562

19. Ibanez L, Potau N, Marcos MV, De Zegher F 2000 Adrenal hyperandrogenism in adolescent girls with a history of low birthweight and precocious pubarche. Clin Endocrinol (Oxf) 53:523-527

20. Ibanez L, Potau N, de Zegher F 1999 Precocious pubarche, dyslipidemia, and low IGF binding protein-1 in girls: relation to reduced prenatal growth. Pediatr Res 46:320 322

21. Ibanez L, Ferrer A, Marcos MV, Hierro FR, de Zegher F 2000 Early puberty: rapid progression and reduced final height in girls with low birth weight. Pediatrics 106:E72

22. Hiyaoka A, Yoshida T, Cho F, Goto N 1989 Growth curves of body weight changes in laboratory-bred female African green monkeys (Cercopithecus aethiops). Jikken Dobutsu 38:239-244

23. Da Silva P, Aitken RP, Rhind SM, Racey PA, Wallace JM 2001 Influence of placentally mediated fetal growth restriction on the onset of puberty in male and female lambs. Reproduction 122:375-383

24. Bacallao J, Amador M, Hermelo M 1996 The relationship of birthweight with height at 14 and with the growing process. Nutrition 12:250-254

25. Bennett F, Watson-Brown C, Thame M, Wilks R, Osmond C, Hales N, Barker D, Forrester T 2002 Shortness at birth is associated with insulin resistance in pre-pubertal Jamaican children. Eur J Clin Nutr 56:506-511

26. Parsons TJ, Power C, Manor O 2001 Fetal and early life growth and body mass index from birth to early adulthood in 1958 British cohort: longitudinal study. BMJ 323:1331-1335

27. Gluckman PD, Pinal CS 2003 Regulation of fetal growth by the somatotrophic axis. J Nutr 133:1741S-1746S

28. Walker SP, Gaskin PS, Powell CA, Bennett FI 2002 The effects of birth weight and postnatal linear growth retardation on body mass index, fatness and fat distribution in mid and late childhood. Public Health Nutr 5:391-396

29. Spencer NJ, Logan S 2002 The treatment of parental height as a biological factor in studies of birth weight and childhood growth. Arch Dis Child 87:184-187

30. Wadsworth ME, Hardy RJ, Paul AA, Marshall SF, Cole TJ 2002 Leg and trunk length at 43 years in relation to childhood health, diet and family circumstances; evidence from the 1946 national birth cohort. Int J Epidemiol 31:383-390

31. Chaussain JL, Colle M, Ducret JP 1994 Adult height in children with prepubertal short stature secondary to intrauterine growth retardation. Acta Paediatr Suppl 399:72-73

32. Hokken-Koelega AC, De Ridder MA, Lemmen RJ, Den Hartog H, De Muinck Keizer-Schrama SM, Drop SL 1995 Children born small for gestational age: do they catch up? Pediatr Res 38:267-271

33. Karlberg J, Albertsson-Wikland K 1995 Growth in full-term small-for-gestational-age infants: from birth to final height. Pediatr Res 38:733-739

34. Hack M, Schluchter M, Cartar L, Rahman M, Cuttler L, Borawski E 2003 Growth of very low birth weight infants to age 20 years. Pediatrics 112:e30-e38

35. Ong KK, Preece MA, Emmett PM, Ahmed ML, Dunger DB 2002 Size at birth and early childhood growth in relation to maternal smoking, parity and infant breastfeeding: longitudinal birth cohort study and analysis. Pediatr Res 52:863-867

36. Ong KK, Ahmed ML, Emmett PM, Preece MA, Dunger DB 2000 Association between postnatal catch-up growth and obesity in childhood: prospective cohort study. BMJ 320:967-971

37. Barker DJ 1997 Maternal nutrition, fetal nutrition, and disease in later life. Nutrition 13:807-813

38. Frisch RE 1994 The right weight: body fat, menarche and fertility. Proc Nutr Soc 53:113-129

39. Ong KK, Ahmed ML, Dunger DB 1999 The role of leptin in human growth and puberty. Acta Paediatr Suppl 88:95-98 
40. dos Santos Silva I, De Stavola BL, Mann V, Kuh D, Hardy R, Wadsworth ME 2002 Prenatal factors, childhood growth trajectories and age at menarche. Int J Epidemiol 31:405-412

41. Collins LM, Sayer AG 2001 New Methods for the Analysis of Change. American Psychological Association, Washington, DC

42. McArdle JJ, Bell RQ 2000 An introduction to latent growth models for developmental data analysis. In: Baumert J (ed) Modeling Longitudinal and Multiple-Group Data: Practical Issues, Applied Approaches, and Specific Examples. Lawrence Erlbaum Associates, Hillsdale, NJ, pp 69-107

43. Terasawa E, Nass TE, Yeoman RR, Loose MD, Schultz NJ 1983 Hypothalamic control of puberty in the female rhesus macaque. In: Normal R (ed) Neuroendocrine Aspects of Reproduction. Academic Press, New York, pp 149-182

44. McArdle JJ, Hamagami F 2001 Latent difference score structural models for linear dynamic analyses with incomplete longitudinal data. In: Sayer AG (ed) New Methods for the Analysis of Change. American Psychological Association, Washington, DC, pp $139-175$

45. McArdle JJ, Nesselroade J 1994 Using multivariate data to structure developmental change. In: Reese HW (ed) Life-Span Developmental Psychology. Lawrence Erlbaum Associates, Hillsdale, NJ, pp 223-267

46. Willett JB, Singer JD, Martin NC 1998 The design and analysis of longitudinal studies of development and psychopathology in context: statistical models and methodological recommendations. Dev Psychopathol 10:395-426

47. Price KC, Hyde JS, Coe CL 1999 Matrilineal transmission of birth weight in the rhesus monkey (Macaca mulatta) across several generations. Obstet Gyneco 94:128-134

48. Price KC, Coe CL 2000 Maternal constraint on fetal growth patterns in the rhesus monkey (Macaca mulatta): the intergenerational link between mothers and daughters. Hum Reprod 15:452-457

49. Heck RH 2001 Multilevel modeling with SEM. In: Schumacker RE (ed) New Developments and Techniques in Structural Equation Modeling. Lawrence Erlbaum Associates, Hillsdale, NJ, pp 203-246

50. Willett JB, Sayer AG 1994 Using covariance structure analysis to detect correlates and predictors of individual change over time. Psychol Bull 116:363-381

51. Granger DA, Shirtcliff EA, Zahn-Waxler C, Usher BA, Klimes-Dougan B, Hastings PD 2003 Salivary testosterone diurnal variation and psychopathology in adolescent males and females: individual differences and developmental effects. Dev Psychopathol 15:431-449

52. Hu IT, Bentler PM 1995 Evaluating model fit. In: Hoyle RH (ed) Structural Equation Modeling. Sage Publications, Thousand Oaks, CA, pp 45-73

53. Hofer SM 1999 Assessing personality structure using factor invariance procedures. In: Ostendorf F (ed) Personality Psychology in Europe. Tilburg University Press, Tilburg, The Netherlands, pp 35-49
54. Meredith W, Horn JL 2001 The role of factorial invariance in modeling growth and change. In: Sayer AG (ed) New Methods for the Analysis of Change. American Psychological Association, Washington, DC, pp 204-240

55. Meredith W 1993 Measurement invariance, factor analysis and factorial invariance. Psychometrika 58:525-543

56. Ridgon EE, Schumacker RE, Wothke W 1998 A comparative review of interaction and nonlinear modeling. In: Marcoulides GA (ed) Interaction and Non-linear Effects in Structural Equation. Lawrence Erlbaum Associates, Hillsdale, NJ, pp 1-16

57. Li F, Duncan SC, Duncan TE, Yang-Wallentin F, Acock AC, Hops H 2001 Interaction models in latent growth curves. In: Schumacker RE (ed) New Developments and Techniques in Structural Equation Modeling. Lawrence Erlbaum Associates, Hillsdale, NJ, pp 561-614

58. Bowman JE, Lee PC 1995 Growth and threshold weaning weights among captive rhesus macaques. Am J Phys Anthropol 96:159-175

59. Delemarre-van de Waal HA, van Coeverden SC, Engelbregt MT 2002 Factors affecting onset of puberty. Horm Res 57(suppl 2):15-18

60. Embleton NE, Pang N, Cooke RJ 2001 Postnatal malnutrition and growth retardation: an inevitable consequence of current recommendations in preterm infants? Pediatrics 107:270-273

61. Ehrenkranz RA, Younes N, Lemons JA, Fanaroff AA, Donovan EF, Wright LL, Katsikiotis V, Tyson JE, Oh W, Shankaran S, Bauer CR, Korones SB, Stoll BJ, Stevenson DK, Papile LA 1999 Longitudinal growth of hospitalized very low birth weight infants. Pediatrics 104:280-289

62. Jaquish CE, Tardif SD, Cheverud JM 1997 Interactions between infant growth and survival: evidence for selection on age-specific body weight in captive common marmosets (Callithrix jacchus). Am J Primatol 42:269-280

63. Rasmussen KM, Ausman LM, Hayes KC 1980 Vital statistics from a laboratory breeding colony of squirrel monkeys (Saimiri sciureus). Lab Anim Sci 30:99-106

64. Goy RW, Kemnitz JW 1983 Early, persistent and delayed effects of virilizing substances delivered transplacentally to female rhesus fetuses. In: Zbinden G (ed) Application of Behavioral Pharmacology in Toxicology. Raven, New York, pp 303-314

65. Terasawa E, Noonan JJ, Nass TE, Loose MD 1984 Posterior hypothalamic lesions advance the onset of puberty in the female rhesus monkey. Endocrinology 115:22412250

66. Feldman PJ, Dunkel-Schetter C, Sandman CA, Wadhwa PD 2000 Maternal social support predicts birth weight and fetal growth in human pregnancy. Psychosom Med 62:715-725

67. Moffitt TE, Caspi A, Belsky J, Silva PA 1992 Childhood experience and the onset of menarche: a test of a sociobiological model. Child Dev 63:47-58 